\title{
Associations of vitamin D status with markers of metabolic health: A community- based study in Shanghai, China
}

\section{Authors: Wei Zhu and Daniel P. Heil}

NOTICE: this is the author's version of a work that was accepted for publication in Diabetes and Metabolic Syndrome: Clinical Research and Reviews. Changes resulting from the publishing process, such as peer review, editing, corrections, structural formatting, and other quality control mechanisms may not be reflected in this document. Changes may have been made to this work since it was submitted for publication. A definitive version was subsequently published in Diabetes and Metabolic Syndrome: Clinical Research and Reviews, volume 12, issue 5, September 2018, DOI\#10.1016/j.dsx.2018.04.010

Zhu, Wei, and Daniel P. Heil. "Associations of vitamin D status with markers of metabolic health: A community-based study in Shanghai, China." Diabetes and Metabolic Syndrome:

Clinical Research and Reviews 12, no. 4 (April 2018): 727-732. DOI:10.1016/j.dsx.2018.04.010. 


\title{
Original Article
}

\section{Associations of vitamin D status with markers of metabolic health: A community-based study in Shanghai, China}

\author{
Wei Zhu ${ }^{\mathrm{a}, \mathrm{b}}$, Daniel P. Heil ${ }^{\mathrm{a}, *}$ \\ a Department of Health and Human Development, Montana State University, Bozeman, MT, 59717, USA \\ ${ }^{\mathrm{b}}$ Department of Nutrition, Shanghai Institute of Health Sciences, Shanghai, 201318, China
}

\begin{abstract}
A B S T R A C T
Aims: This study investigated the associations of vitamin D status (i.e., serum 25(OH)D concentration) with markers of metabolic health and metabolic syndrome (MS), as well as possible gender differences in these associations, with metabolic syndrome (MS) for a sample from Shanghai, China.

Methods: Demographic and anthropometric data, as well as 25-hydroxyvitamin D (serum 25(OH)D), blood glucose, and lipid concentrations were obtained for 508 urban residents aged 19-70 years. After grouping into tertiles according to their serum 25(OH)D concentrations, linear and logistic regressions were used to evaluate associations between serum 25(OH)D concentration and risk factors for MS across tertiles.

Results: A $1 \mathrm{ng} / \mathrm{mL}$ increase in 25(OH)D was associated with a significant decrease in total cholesterol by $0.25 \mathrm{mmol} / \mathrm{L}[95 \% \mathrm{CI}:(-0.44,-0.05) ; P=0.014]$ for the third tertile, with reference to the first tertile. Also, $1 \mathrm{ng} / \mathrm{mL}$ increase in $25(\mathrm{OH}) \mathrm{D}$ was associated with a significant decrease in LDL by $0.18 \mathrm{mmol} / \mathrm{L}$ [ $95 \% \mathrm{CI}$ : $(-0.35,-0.02) ; P=0.026]$ for the third tertile. In addition, participants in the third tertile had a $54 \%$ reduction in the OR for MS [95\% CI: $(-1.10,-0.02), P=0.041]$. Lastly, while there was no gender difference in vitamin D deficiency status, the non-MS women had significantly higher 25(OH)D level than those with MS $(30.1 \pm 5.8$ vs. $28.5 \pm 5.9 \mathrm{ng} / \mathrm{mL}, P=0.035)$, while no such difference was observed for men. Conclusions: Higher serum 25(OH)D concentration was associated with a better metabolic profile and thus a lower risk for developing MS in urban Shanghai residents of China.
\end{abstract}

\section{Introduction}

Vitamin D is a hormone that has long been related to bone metabolism. Recent evidence, however, has suggested links between lower vitamin D status and higher susceptibility for type 2 diabetes (T2DM) [1], dyslipidemia [2], hypertension, and obesity [3], all of which are major components of metabolic syndrome (MS). Given that the vitamin D receptor has been found in tissues throughout the body, it is likely that vitamin D is important for more than calcium homeostasis and bone metabolism [4].

There are two major sources of vitamin D: dietary intake (i.e., dairy products, fatty fish, etc.) and solar UV-radiation, the latter of which stimulates the conversion of 7-dehydrocholesterol to pre-vitamin $\mathrm{D}$, which is then converted to 25-hydroxyvitamin $\mathrm{D}$ $(25(\mathrm{OH}) \mathrm{D})$. Vitamin D is mainly stored in the liver and circulation in the form of $25(\mathrm{OH}) \mathrm{D}$. Thus, serum concentration of $25(\mathrm{OH}) \mathrm{D}$ is generally considered the best indicator of vitamin $\mathrm{D}$ status. When activated in the kidney [4], 25(OH)D is converted to 125dihydroxyvitamin $\mathrm{D}$, participating in calcium homeostasis. Recent literature has shown positive association between serum 25(OH)D, the storage form of vitamin $\mathrm{D}$, and insulin sensitivity [5]. The 125dihydroxyvitamin $\mathrm{D}$, the activated form of vitamin $\mathrm{D}$, is considered a negative endocrine regulator of the renin-angiotensin system [6], and thus helps regulate blood pressure. Vitamin D deficiency is also responsible for intracellular calcium imbalance and, consequently, the stimulation of lipogenic gene expression, which, in turn, increases lipogenesis and impedes lipolysis, causing the net effect of adiposity and dyslipidemia [7].

Given that vitamin D plays a protective role in metabolic health, it is considered beneficial to have a good vitamin D status (i.e., a higher serum 25(OH)D concentration) [8]. However, vitamin D deficiency is still prevalent in the general population worldwide, under-recognized and under-treated [9]. Unlike the United States, vitamin D fortified foods are not commonly available in China and it is still uncommon to use vitamin D supplements among the Chinese populations of all ages [10]. Given that the vitamin D status in the Chinese population is unclear [11], our current study 
primarily aimed to investigate the serum 25(OH)D concentration and its associations with individual metabolic biomarkers (i.e., serum lipids and glucose) for identifying metabolic syndrome in a community-based population in Shanghai, China. In addition, women of certain age groups (i.e., pregnant or lactating women, postmenopausal women, etc.) are suggested to have higher calcium and vitamin $\mathrm{D}$ intakes due to their physiological needs [12]. As such, it is possible that vitamin D deficiency could have more influence on women's metabolic health than for men. To our knowledge, little attention has been addressed to this issue. Our secondary purpose, therefore, was to explore the possible gender differences in the relationships of vitamin $\mathrm{D}$ and metabolic syndrome.

\section{Methods}

\subsection{Study design and sample}

Data for this study were originally collected as part of the Study of Urban Residents Eating-out Behavior (SUREB) [13], a crosssectional community-based survey that has evaluated the diningout behaviors and nutritional status of urban residents in Shanghai, China. The informed consent for the SUREB study was approved by the Changhai Hospital Ethics Committee (CHEC2012-099), Shanghai, China. Data were collected using cluster sampling from various districts of Shanghai between 2012 and 2014. A total of 1032 participants, aged 18 to 74 years, were recruited to answer questionnaires that included self-reported demographic information, dining-out behaviors, and other lifestyle issues. Half of the participants were randomly selected to participate in further examinations, which included the collection of anthropometric measures and a fasting venous blood draw. In the present study, we only included those participants who had blood test results, and further excluded those with missing data for anthropometric measurements.

\subsection{Questionnaires}

Each participant answered a self-reported questionnaire, including age, gender, education level, total annual income, and lifestyle factors (i.e., cigarette smoking, alcohol use, sleep duration, appetite, and outdoor physical activity (PA)). Current smokers were defined as those who consume at least one cigarette per day. Alcohol use was classified as either "Yes" or "No" when asked if it was consumed on a daily basis. Sleep duration was calculated as the average self-reported sleep time for the previous three nights. The time spent performing outdoor PA (hours/week) were calculated as the product of mins/day of daily PA and weekly frequency (days/week) and then converted to hours/week.

\subsection{Anthropometric measures and blood tests}

Participants arrived for examination between 8:00 and 10:00 a. m. after an overnight fast. The participants were asked to wear light clothing and to void their bladders before measurements. Body height was measured barefoot using a stadiometer to the nearest $0.1 \mathrm{~cm}$, and body mass was obtained to the nearest $0.1 \mathrm{~kg}$ using a digital scale. Waist circumference (WC) was measured using a plastic tape measure to the nearest $0.1 \mathrm{~cm}$, and body mass index (BMI, $\mathrm{kg} / \mathrm{m}^{2}$ ) was calculated as body mass $(\mathrm{kg})$ divided by body height $(\mathrm{m})$ squared. After sitting quietly for a minimum of $5 \mathrm{~min}$, systolic and diastolic blood pressure (SBP and DBP, respectively) were measured on the left arm at heart level in a seated position using a standard mercurial sphygmomanometer. Venous blood samples were collected into vacuum test tubes and were sent to the clinical laboratory of Changhai Hospital within

Table 1

Demographic and self-report survey responses for participants by tertiles of serum 25(OH)D concentration ( $n=508)$.

\begin{tabular}{|c|c|c|c|c|}
\hline & \multicolumn{3}{|c|}{ Serum 25(OH)D Tertiles } & \multirow[t]{2}{*}{$P$-value for trend ${ }^{1}$} \\
\hline & Tertile $1(n=170)$ & Tertile $2(\mathrm{n}=170)$ & Tertile $3(n=168)$ & \\
\hline Serum 25(OH)D $(\mathrm{ng} / \mathrm{mL})$ & $23.2 \pm 3.4^{2}$ & $30.0 \pm 1.6$ & $35.9 \pm 2.5$ & $<0.001$ \\
\hline Women & $115(67.6)^{3}$ & $111(65.3)$ & $118(70.2)$ & 0.632 \\
\hline BMI $\left(\mathrm{kg} / \mathrm{m}^{2}\right)$ & $23.6 \pm 3.2$ & $23.5 \pm 3.1$ & $23.3 \pm 3.1$ & 0.721 \\
\hline Age (years) & $51.4 \pm 13.4$ & $48.9 \pm 13.3$ & $50.1 \pm 13.0$ & 0.252 \\
\hline Education & & & & 0.023 \\
\hline Elementary & $61(35.9)$ & $82(48.2)$ & $83(49.4)$ & \\
\hline Middle/High school & $59(34.7)$ & $49(28.8)$ & $61(36.3)$ & \\
\hline College or more & $36(21.2)$ & $28(16.5)$ & $17(10.1)$ & \\
\hline Income & & & & 0.023 \\
\hline Low & $59(34.7)$ & $59(34.7)$ & $84(50.0)$ & \\
\hline Medium & $87(51.2)$ & $82(48.2)$ & 67 (39.9) & \\
\hline High & $10(5.9)$ & $18(10.6)$ & $10(6.0)$ & \\
\hline \multicolumn{5}{|l|}{ Lifestyle factors } \\
\hline Current smokers & $23(13.5)$ & $23(13.5)$ & $23(13.7)$ & 0.612 \\
\hline Alcohol use & $12(7.1)$ & $14(8.2)$ & $9(5.4)$ & 0.410 \\
\hline Sleep Duration (hours/day) & $7.1 \pm 1.0$ & $7.0 \pm 1.0$ & $7.0 \pm 1.0$ & 0.569 \\
\hline Outdoor PA (hours/week) & $9.8 \pm 4.7$ & $8.9 \pm 4.9$ & $8.7 \pm 4.8$ & 0.102 \\
\hline \multicolumn{5}{|c|}{ Anthropometric and blood measures } \\
\hline WC $(\mathrm{cm})$ & $84.0 \pm 9.4$ & $83.2 \pm 9.5$ & $83.2 \pm 9.2$ & 0.681 \\
\hline Glucose $(\mathrm{mmol} / \mathrm{L})$ & $5.50 \pm 1.54$ & $5.47 \pm 1.47$ & $5.31 \pm 1.28$ & 0.443 \\
\hline $\mathrm{TG}(\mathrm{mmol} / \mathrm{L})$ & $1.53 \pm 1.01$ & $1.66 \pm 1.93$ & $1.37 \pm 0.96$ & 0.163 \\
\hline $\mathrm{TC}(\mathrm{mmol} / \mathrm{L})$ & $5.01 \pm 0.99$ & $4.85 \pm 0.89$ & $4.75 \pm 0.87$ & 0.046 \\
\hline LDL-C (mmol/L) & $3.04 \pm 0.81$ & $2.90 \pm 0.72$ & $2.86 \pm 0.74$ & 0.062 \\
\hline HDL-C (mmol/L) & $1.35 \pm 0.35$ & $1.34 \pm 0.33$ & $1.40 \pm 0.45$ & 0.239 \\
\hline $\mathrm{SBP}(\mathrm{mmHg})$ & $122.4 \pm 16.4$ & $121.8 \pm 16.8$ & $121.4 \pm 16.9$ & 0.853 \\
\hline DBP (mmHg) & $80.3 \pm 9.8$ & $80.5 \pm 9.4$ & $79.9 \pm 9.7$ & 0.851 \\
\hline
\end{tabular}

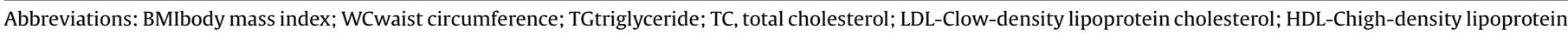
cholesterol; SBPsystolic blood pressure; DBPdiastolic blood pressure.

${ }^{1} p$-value for differences between tertiles using one-way ANOVA and chi-square test for continuous and categorical variables, respectively.

2 Mean \pm SD.

3 Numbers (\%). 
30 min of blood draw. Blood glucose was determined enzymatically. Total cholesterol (TC), triglyceride (TG), and high- and lowdensity lipoprotein cholesterol (HDL-C and LDL-C) concentrations were determined using an automated enzymatic analyzer (Automatic Analyzer 7080, Hitachi, Tokyo, Japan). Finally, serum $25(\mathrm{OH}) \mathrm{D}$ concentrations were determined using enzyme immunoassays (human ELISA assay kit, Cayman chemical Co., USA).

\subsection{Criteria and definitions}

Using the serum $25(\mathrm{OH}) \mathrm{D}$ concentration, vitamin D status was defined as deficient $(<20 \mathrm{ng} / \mathrm{mL})$, insufficient $(20-30 \mathrm{ng} / \mathrm{mL})$, or sufficient (>30 ng/mL) [14]. Participants were defined as having MS when they were identified as having at least three of the following risk factors [15]: 1) Abdominal obesity, which was defined as a $W C \geq 85 \mathrm{~cm}$ for women and $\geq 90 \mathrm{~cm}$ for men according to the criteria for the Chinese population [16]; 2) Serum TG $\geq 1.7 \mathrm{mmol} / \mathrm{L}$; 3) $\mathrm{HDL}-\mathrm{C}<1.1 \mathrm{mmol} / \mathrm{L}$ for women and HDL-C $<0.9 \mathrm{mmol} / \mathrm{L}$ for men; 4) Hypertensive, which was defined as an SBP $\geq 130 \mathrm{mmHg}$ and $\mathrm{DBP} \geq 85 \mathrm{mmHg}$ (or treated hypertension); 5) Fasting blood glucose $\geq 6.1 \mathrm{mmol} / \mathrm{L}$. Lastly, participants were also statistically divided into tertiles according to serum 25(OH)D concentration ( $n=170,170$, and 168 for the 1 st, 2 nd, and 3rd tertiles, respectively) where Tertile 1 ha d the lowest mean $25(\mathrm{OH}) \mathrm{D}$ concentration and Tertile 3 ha d the highest mean 25(OH)D concentration.

\subsection{Statistics}

Descriptive data were presented as mean \pm SD unless otherwise specified. Gender differences in vitamin D status, dairy intake, and outdoor PA were examined using independent $t$-test and Satterthwaite approximation, the latter of which is a method for handling two-sample comparisons with different sample sizes or unequal variances. The statistical results for the Satterthwaite approximation analyses, however, were identical to the originallyplanned t-tests, so the results of the t-tests were reported. Across the 25(OH)D tertiles, one-way ANOVA and chi-square test were used to determine the differences for continuous and categorical variables, respectively. Linear trend for serum lipids and glucose concentration were assessed across $25(\mathrm{OH}) \mathrm{D}$ tertiles using linear regression analyses, whereas logistic regression was used to determine the odds ratio (OR) for MS with reference to the lowest serum 25(OH)D tertile. All statistical tests were evaluated for significance at the 0.05 alpha level, while all statistical analyses were conducted using SPSS 13.0 for windows (SPSS Inc., Chicago, USA).

\section{Results}

From the original sample of 1032 , blood test data was collected on 529 participants, but missing anthropometric data for 21 of these reduced the final sample size to 508 participants. A summary of demographic and self-report survey data for the 164 men and 344 women, stratified by tertiles of serum $25(\mathrm{OH}) \mathrm{D}$ concentration, is provided in Table 1.

\subsection{Serum 25(OH)D and demographics}

Across the tertiles, no age or gender differences were observed. However, low income and less-educated participants had higher serum 25(OH)D concentrations ( $P=0.023$ for both comparisons). Further, no differences were observed for any of the lifestyle factors (i.e., cigarette smoking, alcohol use, sleepy duration, outdoor PA) between the tertiles. For the blood measures, we found a significantly lower serum TC and LDL-C concentrations in the third tertile $(P<0.05$ for both) when compared to the first and the second tertiles, whereas no significant difference were observed for WC, glucose, TG, HDL-C, SBP or DBP.

\subsection{Serum 25(OH)D and dairy intake, physical activity, gender differences}

With a sample average serum $25(\mathrm{OH}) \mathrm{D}$ concentration of $29.7 \pm 5.8 \mathrm{ng} / \mathrm{mL}$ (mean \pm SD; Table 2 ), $5.3 \%$ of the sample was classified as vitamin D deficient, an additional $44.7 \%$ was classified as vitamin $D$ insufficient, and the remaining $50.0 \%$ were vitamin $D$ sufficient. Further, there were no gender differences in the prevalence of vitamin D deficiency, insufficiency, or sufficiency. However, female participants had a significantly higher dairy intake $(P=0.005)$ and tended to be more physically active outdoors, though this trend was not statistically significant $(P=0.091)$ (Table 2). Those participants classified with having MS $(n=114)$ had a lower mean serum 25(OH)D concentration than all other sample participants $(28.8 \pm 5.7$ vs. $30.0 \pm 5.9 \mathrm{ng} / \mathrm{mL}$ and $P=0.057$; not shown in the figures). However, when stratified by gender, as shown in Fig. 1, women with MS had a significantly lower serum 25(OH)D concentration than those without MS $(28.5 \pm 5.9$ vs. $30.1 \pm 5.8 \mathrm{ng} / \mathrm{mL} ; P=0.035)$, whereas no such difference was observed for their male counterparts $(29.6 \pm 5.4$ vs. $29.9 \pm 6.1 \mathrm{ng} / \mathrm{mL} ; P=0.771)$.

\subsection{Serum 25(OH)D and metabolic profile}

The regression results provided in Table 3 highlight the linear rate of change in $25(\mathrm{OH}) \mathrm{D}$ relative to changes in serum lipids and glucose with reference to the first tertile. The regression coefficient ( $\beta$, or the slope of the regression line) for the regression of $25(\mathrm{OH}) \mathrm{D}$ on TC tertiles shows that a $1 \mathrm{ng} / \mathrm{mL}$ increase in $25(\mathrm{OH}) \mathrm{D}$ was associated with a significant decrease in TC by $0.25 \mathrm{mmol} / \mathrm{L}$ [95\% CI: $(-0.44,-0.05) ; P=0.014]$ for the third tertile. Also, $1 \mathrm{ng} / \mathrm{mL}$ increase in 25(OH)D was associated with a significant decrease in LDL by $0.18 \mathrm{mmol} / \mathrm{L}$ [95\% CI: $(-0.35,-0.02) ; P=0.026]$ for the third

Table 2

Vitamin D status, dairy intake and outdoor physical activity (PA) in participants by gender.

\begin{tabular}{|c|c|c|c|c|}
\hline & All Subjects $(n=508)$ & Men $(n=164)$ & Women $(n=344)$ & P-value ${ }^{1}$ \\
\hline Serum $25(\mathrm{OH}) \mathrm{D}(\mathrm{ng} / \mathrm{mL})$ & $29.7 \pm 5.8^{2}$ & $29.8 \pm 5.8$ & $29.6 \pm 5.8$ & 0.645 \\
\hline Vitamin D status ${ }^{3}$ & & & & 0.979 \\
\hline Deficient & $27(5.3)^{4}$ & $9(5.5)$ & $18(5.2)$ & \\
\hline Insufficient & $227(44.7)$ & $74(45.1)$ & $153(44.5)$ & \\
\hline Sufficient & $254(50.0)$ & $81(49.4)$ & $173(50.3)$ & \\
\hline Dairy Intake $(\mathrm{g} / \mathrm{d})$ & $195.8 \pm 154.8$ & $167.8 \pm 137.9$ & $209.2 \pm 160.7$ & 0.005 \\
\hline Outdoor PA (hours/week) & $9.2 \pm 4.8$ & $8.6 \pm 4.9$ & $9.4 \pm 4.7$ & 0.091 \\
\hline
\end{tabular}

1 p-value for gender differences using independent $t$-test for continuous variables and chi-square test for categorical variables.

2 Mean \pm SD.

${ }^{3}$ Vitamin D status was defined, according to serum $25(\mathrm{OH}) \mathrm{D}$ concentration, as deficient ( $\left.<20 \mathrm{ng} / \mathrm{mL}\right)$, insufficient $(20 \sim 30 \mathrm{ng} / \mathrm{mL})$, or sufficient $(>30 \mathrm{ng} / \mathrm{mL})$.

4 Numbers (\%). 


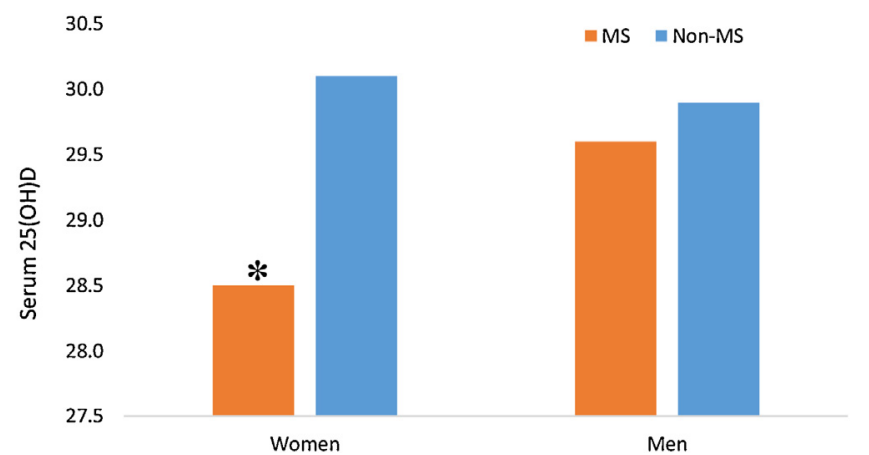

Fig. 1. Mean Serum 25(OH)D concentration in participants with or without metabolic syndrome (MS). Serum 25(OH)D level was significantly lower $\left(^{*}\right)$ in female participants with MS than those without MS $(28.5 \pm 5.9 \mathrm{vs} .30 .1 \pm 5.8 \mathrm{ng} / \mathrm{mL}$; $P=0.035)$; No such difference was observed for the male participants $(29.6 \pm 5.4 \mathrm{vs}$. $29.9 \pm 6.1 \mathrm{ng} / \mathrm{mL} ; P=0.771)$.

Table 3

Linear trend for serum lipids and glucose across 25(OH)D tertiles.

\begin{tabular}{llll}
\hline & $\beta^{1}$ & $95 \% \mathrm{CI}$ & P-value \\
\hline TC & & & \\
Tertile 2 & -0.15 & $(-0.34,0.05)$ & 0.138 \\
Tertile 3 & -0.25 & $(-0.44,-0.05)$ & 0.014 \\
& & & \\
LDL & & $(-0.31,0.01)$ & 0.076 \\
Tertile 2 & -0.15 & $(-0.35,-0.02)$ & 0.026 \\
Tertile 3 & -0.18 & & \\
& & $(-0.09,0.07)$ & 0.803 \\
HDL & -0.01 & $(-0.03,0.13)$ & 0.184 \\
Tertile 2 & 0.05 & & 0.396 \\
Tertile 3 & & $(-0.17,0.42)$ & 0.290 \\
TG & & $(-0.45,0.13)$ & \\
Tertile 2 & 0.13 & & 0.855 \\
Tertile 3 & -0.16 & $(-0.34,0.29)$ & 0.236 \\
Glucose & & $(-0.50,0.13)$ &
\end{tabular}

Abbreviations: TG: triglyceride; TC, total cholesterol; LDL-C: low-density lipoprotein cholesterol; HDL-C: high-density lipoprotein cholesterol; MS: metabolic syndrome.

1 Regression coefficient $(\beta)$ for the second and third tertiles were obtained using linear regression model with reference to the first tertile.

tertile. In addition, participants in the third tertile had a $54 \%$ reduction in the OR for MS [95\% $\mathrm{CI}:(-1.10,-0.02) ; P=0.041]$ with reference to the first tertile. Finally, after controlling for age, BMI, TG and HDL-C, all these associations (e.g., 25(OH)D with TC, LDL, and MS) remained significant.

\section{Discussion}

This study appears to be the first to describe vitamin D status for residents of a large city in China. As such, these results represent a step forward in understanding determinants of metabolic health risk in this population.

\subsection{Serum 25(OH)D status}

In our current study, $5.3 \%$ and $44.7 \%$ of the sample were identified as either vitamin D deficient or insufficient, respectively, while $50.0 \%$ of the sample was identified as being vitamin D sufficient. Han et al. [11] studied a population in Eastern China, and reported an $83.3 \%$ rate of vitamin D deficiency in their sample. This huge difference in vitamin D status (83.3\% deficiency in the Han study versus only 5.3 deficiency for the current study) may be due to systematic differences in dietary availability and/or sun exposure between the two samples. Shanghai residents, for example, have a plentiful seafood supply due to the geographic location of this coastal city. Thus, it is possible that this population has a higher consumption of fatty fish in general, which should contribute to a higher 25(OH)D level than Han's land-locked Eastern China sample. In addition, our study collected data in spring and summer, during which participants likely experienced plenty of sun exposure, while Han's study didn't specify the estimates about sun exposure. Regardless, the current study results for this relatively small sample from a large urban coastal Chinese city suggests that vitamin D status was substantially higher than that previously reported for non-coastal Chinese residents.

\subsection{Serum 25(OH)D and metabolic health risks}

The results of the current study also found that higher serum 25 $(\mathrm{OH}) \mathrm{D}$ concentration was associated with a better serum lipids profile, as well as a $54 \%$ reduction in the odds for being classified with MS when comparing the lowest with the highest tertile. These results are consistent with those from previous studies, such as Maki et al. [2], who found a graded decrease in the prevalence of metabolic syndrome from the lowest to the highest 25(OH)D tertile (31\%, 14\%, and 10\%, respectively). Similarly, Reis et al. [17] also reported an inverse association of $25(\mathrm{OH}) \mathrm{D}$ with MS, independent of potential confounding factors, calcium intake, and PTH among US adults. The above results suggest that a good vitamin D status may be positively related to both serum lipids and the incidence of MS in this sample of Chinese residents of Shanghai.

In the present study, women had a significantly higher dairy intake than men and tended to be more physically active outdoors. Despite these anticipated contributors to a higher vitamin D status for women, no difference was observed between men and women in serum $25(\mathrm{OH}) \mathrm{D}$ concentration. It is possible that the extra vitamin $\mathrm{D}$ intake might have been contributed to calcium absorption and bone metabolism, especially in postmenopausal women due to estrogen deficiency. Interestingly, we also found that women with MS had a significantly lower serum 25(OH)D concentration than women without MS (28.5 \pm 5.9 vs. $30.1 \pm 5.8 \mathrm{ng} / \mathrm{mL} ; P=0.035)$, while no such difference was observed for their male counterparts $(29.6 \pm 5.4$ vs. $29.9 \pm 6.1 \mathrm{ng} / \mathrm{mL}$; $P=0.771$ ). Al-Dabhani et al. [18] assessed the association of vitamin D status with MS in their whole sample and found that serum vitamin D was $8 \%$ lower in individuals with metabolic syndrome (RR: $0.92,95 \% \mathrm{CI}$ : $0.87-0.98, P$-value $=0.01$ ) compared to individuals without metabolic syndrome. In our current study, we observed a borderline significance in the difference of serum $25(\mathrm{OH}) \mathrm{D}$ concentration between individuals with and without MS $(28.8 \pm 5.7$ vs. $30.0 \pm 5.9 \mathrm{ng} / \mathrm{mL}$, respectively; $P=0.057)$, however, the difference was significant only after stratifying by gender. These gender differences suggest that women with lower vitamin D status might be more susceptible to metabolic diseases than men within this sample of urban Chinese.

Investigation of serum lipid levels could possibly explain the beneficial effect of a better vitamin $D$ status on incidents of cardiovascular diseases (CVD) and mortality. In our study, serum TC, LDL-C, and TG showed a decreasing trend while HDL-C saw an increasing trend from the first to the third tertiles of 25(OH)D. Furthermore, a $1 \mathrm{ng} / \mathrm{mL}$ increase in $25(\mathrm{OH}) \mathrm{D}$ in the third tertile was associated with a significant decrease in TC and LDL-C by $0.25 \mathrm{mmol} / \mathrm{L}$ and $0.18 \mathrm{mmol} / \mathrm{L}$, respectively. These results are in line with those of a prospective study [19] that investigated the association of low 25(OH)D levels with all-cause mortality and CVD risks in 13,331 nationally representative adults from the Third 
National Health and Nutrition Examination Survey (NHANES III). Analyses from the NHANES III indicated a negative association of TC and LDL-C with quintiles of serum 25(OH)D concentration. There is some inconsistency in the literature, however [20-22]. Jorde et al. [20], reported serum TC and LDL-C increased, instead of decreased, across quartiles of serum $25(\mathrm{OH}) \mathrm{D}$ concentration (i.e., from the lowest to the highest quartiles), which contradicts the findings of our study, although they did find a decrease in TG and increase in $\mathrm{HDL}$ across the serum 25(OH)D quartiles. The inconsistency between these studies could be explained by different populations, methodology, etc.

\subsection{Possible mechanisms underlying vitamin D deficiency}

While the mechanisms underlying these associations are still not clear, the research literature suggests that vitamin D deficiency could: 1) Initiate the cholesterol de novo synthesis through the activation of the sterol regulatory element binding protein 2 (SREBP2) [23]; 2) Accelerate foam cell formation through the c-Jun $\mathrm{N}$-terminal kinase pathway, a process that eventually leads to atherosclerosis [24]; 3) Reduce the blunting effect of the endoplasmic reticulum (ER) products of insulin-induced gene-2 (Insig-2) on SREBP2 [25] (The Insig-2 prohibits the translocation of SREBP-2 to the nucleus, and inhibits cholesterol biosynthesis); 4) Induce insulin resistance by upregulating the peroxisome proliferated-activated receptor-gamma $(P P A R-\gamma)$ expression, which causes impaired $\beta$-cell proliferation [26]. In contrast, 125 $(\mathrm{OH})_{2} \mathrm{D}_{3}$ supplementation has been implied to be protective against cardiometabolic diseases by reducing macrophage cholesterol uptake [24], suppressing foam cell formation [25], and attenuating insulin resistance [26]. In addition, there might also be a link between serum 25(OH)D concentration and cardiometabolic diseases. Mackawy et al.[27] investigated the influence of VDR gene polymorphisms on chronic inflammation and MS components in type 2 diabetic patients. The authors found that the TT genotype of the VDR 2,228,570 C > T (Fok I VDR) was significantly more frequent in diabetic patients with MS than diabetic patients without MS and healthy individuals. Fok I VDR was also found to be significantly associated with the serum 25(OH)D concentration, lipid profiles, insulin resistance index (HOMA-IR) and IL-6 plasma in diabetic patients. Genetic variants of Fok I VDR are also related to higher susceptibility to ischemic stroke - i.e., The presence of the ff genotype had 2.97-fold risk of ischemic stroke and had significantly higher cholesterol levels as compared to the FF carriers [28]. These clues provide further explanations to the link that connects low vitamin D status and individual metabolic biomarkers.

\subsection{Possible study limitations and future directions}

One limitation of this study is that we collected data during a specific window of time during the year (i.e., spring and summer) instead of throughout the year. The solar UV-radiation is the highest from late spring to early fall while staying relatively low during the other months. Future studies should expand the data collection period to at least a whole year period with an emphasis on seasonal evaluations. Secondly, Shanghai residents have a plentiful fresh seafood supply due to the geographic location of this coastal city. It is possible that this population has a higher consumption of fatty fish in general, which contributes to a higher $25(\mathrm{OH}) \mathrm{D}$ level. Thus, this population might not be representative of all urban Chinese residents. Thirdly, our sample size is relatively small due to limited funding support. Finally, future research should further investigate the causal effect of vitamin D on metabolic biomarkers through prospective and intervention studies.

\section{Conclusions}

This study, which provides the first description of vitamin D status for residents of a large urban coastal city in China, provides a relatively rare view within the single most populous country in the world. Within our small sample, low serum 25(OH)D concentration was associated with a higher risk for metabolic syndrome, where the women with lower vitamin D status were statistically more susceptible to metabolic syndrome than their male counterparts. Thus, vitamin D status may be a relevant biomarker, especially for women, for underlying metabolic disfunction that ultimately causes higher rates of metabolic syndrome. To verify this supposition, however, future studies will need to overcome the notable limitation of the current study which include an observational design, a small sample size, and limited seasonal measurements.

\section{Funding}

This work was supported by the FeiYue Scientific Research Fund of the Shanghai Municipality (FY200-A5-1-01).

\section{Acknowledgements}

We thank Jinhua Zhou and Ying Wang for contributing their time collecting data for this study. This work was supported by the FeiYue Scientific Research Fund of the Shanghai Municipality (FY200-A5-1-01).

\section{References}

[1] Pannu P.K., Piers LS, Soares MJ, Zhao Y, Ansari Z. Vitamin D status is inversely associated with markers of risk for type 2 diabetes: a population based study in Victoria, Australia. PloS One 2017;12(6):e0178825.

[2] Maki KC, Rubin MR, Wong LG, McManus JF, Jensen CD, Marshall JW, et al. Serum 25-hydroxyvitamin D is independently associated with high-density lipoprotein cholesterol and the metabolic syndrome in men and women. J Clin Lipidol. 2009;3(August 4):289-96.

[3] Major GC, Chaput J-P, Ledoux M, St-Pierre S, Anderson GH, Zemel MB, et al. Recent developments in calcium-related obesity research. Obes Rev Off J Int Assoc Study Obes 2008;9(September 5):428-45.

[4] Jorde R, Grimnes G. Vitamin D and metabolic health with special reference to the effect of vitamin D on serum lipids. Prog Lipid Res 2011;50(October 4):303-12

[5] Kamycheva E, Jorde R, Figenschau Y, Haug E. Insulin sensitivity in subjects with secondary hyperparathyroidism and the effect of a low serum 25hydroxyvitamin D level on insulin sensitivity. J Endocrinol Invest 2007;30 (February 2):126-32.

[6] Li YC, Kong J, Wei M, Chen Z-F, Liu SQ, Cao L-P. 1,25-Dihydroxyvitamin D(3) is a negative endocrine regulator of the renin-angiotensin system. J Clin Invest. 2002;110(July 2):229-38.

[7] Zemel MB. Mechanisms of dairy modulation of adiposity. J Nutr. 2003;133 (January 1):252S-6S.

[8] Parker J, Hashmi O, Dutton D, Mavrodaris A, Stranges S, Kandala N-B, et al. Levels of vitamin D and cardiometabolic disorders: systematic review and meta-analysis. Maturitas. 2010;65(March 3):225-36.

[9] Holick MF, Chen TC. Vitamin D deficiency: a worldwide problem with health consequences. Am J Clin Nutr. 2008;87(April 4):1080S-6S.

[10] Lu L, Yu Z, Pan A, Hu FB, Franco OH, Li H, et al. Plasma 25-hydroxyvitamin D concentration and metabolic syndrome among middle-aged and elderly Chinese individuals. Diabetes Care. 2009;32(July 7):1278-83.

[11] Han B, Wang X, Wang N, Li Q, Chen Y, Zhu C, et al. Investigation of vitamin D status and its correlation with insulin resistance in a Chinese population. Public Health Nutr 2017;20(Junuary 9):1602-8.

[12] A.C. Ross, C.L. Taylor, A.L. Yaktine, H.B. Del Valle. Dietary reference intakes for calcium and vitamin D [internet]. Available from: https://www.nap.edu/read/ 13050/chapter/1.

[13] Zhou J, Guo J, Cai D, Zhu W, Cao X. Influence of dietary structures on obesity in Shanghai urban citizens who frequently dine out. Amino Acids Biot Resour. 2013;35(2):64-8.

[14] Holick MF, Vitamin D. Deficiency. N Engl J Med. 2007;357(July 3):266-81.

[15] Alexander CM, Landsman PB, Teutsch SM, Haffner SM. Third national health and nutrition examination survey (NHANES III), national cholesterol education program (NCEP). NCEP-defined metabolic syndrome, diabetes, and prevalence of coronary heart disease among NHANES III participants age 50 years and older. DiAbetes 2003;52(May 5):1210-4. 
[16] Bao Y, Lu J, Wang C, Yang M, Li H, Zhang X, et al. Optimal waist circumference cutoffs for abdominal obesity in Chinese. Atherosclerosis. 2008;201(December 2):378-84.

[17] Reis JP, von Mühlen D, Miller ER. Relation of 25-hydroxyvitamin D and parathyroid hormone levels with metabolic syndrome among US adults. Eur J Endocrinol Eur Fed Endocr Soc 2008;159(July 1):41-8.

[18] Al-Dabhani K, Tsilidis KK, Murphy N, Ward HA, Elliott P, Riboli E, et al. Prevalence of vitamin D deficiency and association with metabolic syndrome in a Qatari population. Nutr Diabetes 2017;7(April 4):e263.

[19] Melamed ML, Michos ED, Post W, Astor B. 25-hydroxyvitamin D levels and the risk of mortality in the general population. Arch Intern Med. 2008;11(August 15):1629-37.

[20] Jorde R, Figenschau Y, Hutchinson M, Emaus N, Grimnes G. High serum 25hydroxyvitamin D concentrations are associated with a favorable serum lipid profile. Eur J Clin Nutr 2010;64(December 12):1457-64.

[21] Pham T-M, Ekwaru JP, Loehr SA, Veugelers PJ. The relationship of serum 25Hydroxyvitamin D and insulin resistance among nondiabetic canadians: a longitudinal analysis of participants of a preventive health program. PloS One 2015;10(10):e0141081.

[22] Wright CS, Weinheimer-Haus EM, Fleet JC, Peacock M, Campbell WW. The apparent relation between plasma 25-Hydroxyvitamin D and insulin resistance is largely attributable to Central adiposity in overweight and obese adults. J Nutr 2015;145(December 12):2683-9.
[23] Dang R, Jiang P, Cai H, Li H, Guo R, Wu Y, et al. Vitamin D deficiency exacerbates atypical antipsychotic-induced metabolic side effects in rats: involvement of the INSIG/SREBP pathway. Eur Neuropsychopharmacol J Eur Coll Neuropsychopharmacol 2015;25(August 8):1239-47.

[24] Oh J, Weng S, Felton SK, Bhandare S, Riek A, Butler B, et al. 1,25(OH)2 vitamin d inhibits foam cell formation and suppresses macrophage cholesterol uptake in patients with type 2 diabetes mellitus. Circulation 2009;120(August 8):68798.

[25] Li S, He Y, Lin S, Hao L, Ye Y, Lv L, et al. Increase of circulating cholesterol in vitamin $\mathrm{D}$ deficiency is linked to reduced vitamin $\mathrm{D}$ receptor activity via the Insig-2/SREBP-2 pathway. Mol Nutr Food Res 201523(December).

[26] Park S, Kim DS, Kang S. Vitamin D deficiency impairs glucose-stimulated insulin secretion and increases insulin resistance by reducing PPAR- $\gamma$ expression in nonobese type 2 diabetic rats. J Nutr Biochem. 2016:27 (January):257-65.

[27] Mackawy AMH, Badawi MEH. Association of vitamin D and vitamin D receptor gene polymorphisms with chronic inflammation, insulin resistance and metabolic syndrome components in type 2 diabetic Egyptian patients. Meta Gene 2014;2(December):540-56.

[28] Prabhakar P, Majumdar V, Kulkarni GB, Christopher R. Genetic variants of vitamin D receptor and susceptibility to ischemic stroke. Biochem Biophys Res Commun 2015;456(January 2):631-6. 